\title{
Estimation and Comparative of Dynamic Optimal Hedge Ratios of China Gold Futures Based on ECM-GARCH
}

\author{
Pujiang Chen ${ }^{1}$, Zirong Zhuo ${ }^{1} \&$ Jixiang Liu $^{1}$ \\ ${ }^{1}$ School of Jinan University, Guangdong, China \\ Correspondence: Pujiang Chen, School of Jinan University, Guangdong, China. Tel: 86-137-5007-5014. E-mail: \\ 316592902@qq.com
}

Received: December 9, 2015

Accepted: January 4, $2016 \quad$ Online Published: February 20, 2016

doi:10.5539/ijef.v8n3p236

URL: http://dx.doi.org/10.5539/ijef.v8n3p236

\begin{abstract}
In order to avoid the risk of fluctuations in prices, commodity production operators develop future hedge, in which the evaluation of optimal hedge ratios are the core question. On the other hand, since gold plays an increasingly important role in Chinese economic activities, gold hedge becomes a hot topic. We employ gold future prices and spot gold prices in China market in which the time period covered was from January 2014 to June 2015 and calculate the optimal hedge ratios using different static and dynamic models. The static hedge model mainly use Ordinary Least Squares Regression (OLS), Error Correction Model (ECM) and Vector Error Correction Model (VECM) model. In addition, the dynamic hedge model mainly use bivariate GARCH model (BGARCH model). The results show that the efficiency of hedge of ECM-GARCH model is the best over the sample period.
\end{abstract}

Keywords: gold, hedge ratios, ECM-BGARCH, dynamic model, China

\section{Introduction}

Keynes\&Hicks, who came up with the idea hedge, thought that hedge is to establish position in the future market, so as to avoid the risk. This positon is supposed to be in the opposite direction with the spot market. For the method of calculating hedge ratio accurately, researchers had done dozens of studies. Working (1953) challenged the view of hedgers as pure risk minimizers, and devoted himself to expected profit maximization. Johnson (1960) and Stein (1961) integrated the risk avoidance theory of Working. They indicated that one buys or sells futures for the same risk-return reasons that one buys any other security. At present, the research of hedge is mainly divided into two aspects, static methods and dynamic methods.

The static methods assumed that optimal hedge ratio would not fluctuate as time changing. Ederington (1979) proposed the core of hedge is to minimize the variance of asset portfolios, thereby it is reasonable applying OLS method to compute hedge ratio. OLS regression model assumed that distributions of futures and spots prices were irrelevant to time. Chou, Fan and Lee (1996) proposed the error correction model which can estimate the optimal hedge ratios, using two step estimated. Error correction model (ECM) has a better effect in the study of nonstationary time series and co-integration relationship of series. Baillie and Myers (1991) proposed BGARCH model, they used BGARCH model to estimate the optimal hedging ratios in American agricultural products futures. Two dimensions of GARCH (BGARCH) model had made up a defect that GARCH model can not reflect the sequence of the covariance in the study.

Time series of future and spot price have some specific features, leading to inadaptation to some hypothesis in static methods above, for example, serial auto-correlation, conditional heteroscedasticity, nonstationary time series. Therefore, dynamic methods, taking these problems into account, were proposed. Baillie and Myers (1991) proposed BGARCH model, they used BGARCH model to estimate the optimal hedge ratios in American agricultural products futures. Two dimensions of GARCH (BGARCH) model has made up a defect that GARCH model can not reflect the sequence of the covariance in the study. Kroner and Sultan (1993) combined co-integration relationship and time-varying variance, constructed ECM-GAECH model. He applied his model to estimate optimal hedge ratios of some major currencies in the world, including Pound and Canadian Dollar, and got better results.

In this paper, through combining ECM method and BGARCH model, we launch an empirical analysis of optimal 
hedge ratio of gold in China market. Besides, OLS model, ECM model, VECM model are also applied to estimate optimal hedge ratios for comparing. According to these models, we compare the results and provide the optimal hedge ratios that calculate through ECM-BGARCH method.

\section{Methodologies}

\subsection{Minimum Variance Hedge}

Ederington (1979) divided the futures hedging strategy into three categories:

(1) Expected profit maximization theory, namely Working's assume that profit maximization strategy;

(2) Minimum variance or the minimum risk hedge theory;

(3) The utility maximization of portfolio hedging theory.

This article discussed and contrasted of the second in hedge practice.

Assume that the investors use short futures to hedge, the relation of expected return and variance of the portfolio by investors as follows(hedge term from moment $\mathrm{t}-1$ to moment $\mathrm{t}$ ) :

$$
\begin{gathered}
E\left(R_{t}\right)=X_{S} R_{S, t}-X_{F} R_{F, t}-K\left(X_{F}\right) \\
\operatorname{Var}\left(R_{t}\right)=X_{S}^{2} \sigma_{S}^{2}+X_{F}^{2} \sigma_{F}^{2}-2 X_{S} X_{F} \sigma_{S F}
\end{gathered}
$$

where $E\left(R_{t}\right)$ is the portfolio expected gross income in moment $\mathrm{t}, R_{F, t}$ is the futures yields in moment $\mathrm{t}, R_{S, t}$ is the spot yields in moment t, $K\left(X_{F}\right)$ is transaction cost when buy futures. Spot and futures position are denoted by $X_{S}$ and $X_{F}$ respectively. The purpose of investors hedge can be expressed as:

$$
\underset{X_{S}, X_{F}}{\operatorname{Min}} \operatorname{Var}\left(R_{t}\right)=X_{S}^{2} \sigma_{S}^{2}+X_{F}^{2} \sigma_{F}^{2}-2 X_{S} X_{F} \sigma_{S F}
$$

The optimal hedge ratio is:

$$
h^{*}=\frac{X_{F}}{X_{S}}=\frac{\sigma_{S F}}{\sigma_{F}^{2}}
$$

\subsection{Ordinary Least Squares Regression (OLS) Model}

Ordinary least squares model is linear regression model. Specifically, in this paper, changes in spot gold price are regressed on the changes in gold futures price. The regression that we implied in our paper is:

$$
\Delta \ln S_{t}=\mathrm{c}+h \Delta \ln F_{t}+\varepsilon_{t}
$$

in which $\Delta \ln S_{t}$ is spot price variation in day $\mathrm{t}, \Delta \ln F_{t}$ is future price variation in day $t, \mathrm{c}$ represent constant term and $\varepsilon_{t}$ is residual error. $h$ is the coefficient of $\Delta \ln F_{t}$, i.e. the optimal hedge ratio.

\subsection{Error Correction Model (ECM)}

Assume that $\chi$ and $y$ have long-term relation as follows:

$$
y_{t}=\alpha_{0}+\alpha_{1}+\chi_{t}+\mu_{t}
$$

Infrequently, $\chi$ and $y$ are at the equilibrium point. Therefore, the relationship that we observed is short-term or disequilibrium. With first order difference, assume that there are $(1,1)$ order distributed lag model.

$$
y_{t}=\beta_{0}+\beta_{1}+\beta_{2} \chi_{t-1}+\mu_{t} y_{t-1}+\varepsilon_{t}
$$

It reveals that $y$ value not only relevant to value $\chi$ in the period of t but the value of $\chi$ and $y$ in the period of $\mathrm{t}-1$. Then see the deformation of formula.

$$
\begin{gathered}
y_{t}-y_{t-1}=\beta_{0}+\beta_{1} \chi_{t}-\beta_{1} \chi_{t-1}+\beta_{1} \chi_{t-1}+\beta_{2} \chi_{t-1}+\mu y_{t-1}-y_{t-1}+\varepsilon_{t} \\
\text { i.e. } \Delta y_{t}=\beta_{0}+\beta_{1} \Delta \chi_{t}+\left(\beta_{1}+\beta_{2}\right) \chi_{t-1}-(1-\mu) y_{t-1}+\varepsilon_{t}
\end{gathered}
$$

Further,

$$
\Delta y_{t}=\beta_{1} \Delta \chi_{t}-(1-\mu)\left(y_{t-1}-\frac{\beta_{0}}{1-\mu}-\frac{\beta_{1}+\beta_{2}}{1-\mu} \chi_{t-1}\right)+\varepsilon_{t}
$$


If $\alpha_{0}^{\prime}=\frac{\beta_{0}}{1-\mu}, \alpha_{1}^{\prime}=\frac{\beta_{1}+\beta_{2}}{1-\mu}$, then:

$$
\Delta y_{t}=\beta_{1} \Delta \chi_{t}-(1-\mu)\left(y_{t-1}-\alpha_{0}^{\prime}-\alpha_{1}^{\prime} \chi_{t-1}\right)+\varepsilon_{t}
$$

We can find that $y_{t-1}-\alpha_{0}^{\prime}-\alpha_{1}^{\prime} \chi_{t-1}$ reflects disequilibrium error term in period t-1. And we call (11) one order error correction model. Formula (11) can be rewrite as:

$$
\Delta y_{t}=\beta_{1} \Delta \chi_{t}-\lambda e c m+\varepsilon_{t}
$$

Where $\lambda=1-\mu$, and $e c m$ represent error correction term.

The application of ECM model is display as follows. Firstly, because of the co-integration relationship between spot price and future price, we have to apply co-integration regression method to formula below:

Then estimate error correction model:

$$
S_{t}=c+h F_{t}+\varepsilon_{t}
$$

$$
\Delta S_{t}=\alpha\left(S_{t-1}-F_{t-1}\right)+\beta \Delta F_{t}+\sum_{i=1}^{m} \delta_{i} \Delta F_{t-i}+\sum_{j=1}^{n} \theta_{j} \Delta S_{t-j}+e_{t}
$$

$\hat{\beta}$, The OLS estimator of $\beta$, is the optimal hedge ratio.

Chou, Fan, and Lee (1996) modified the error correction model to,

$$
\Delta S_{t}=\alpha \hat{\varepsilon}_{t-\mathrm{i}}+\beta \Delta F_{t}+\sum_{i=1}^{m} \delta_{i} \Delta F_{t-i}+\sum_{j=1}^{n} \theta_{j} \Delta S_{t-j}+e_{t}
$$

In which $\hat{\varepsilon}_{t-1}=S_{t-1}-\left(\hat{c}+\hat{h} F_{t-1}\right)$ is the residual term, i.e. error correction term (ECM).

Using this method to estimate the optimal hedge ratio, we have to calculate formula (13) and then reserve its residual term. After that, through formula (15) we can get the result.

\subsection{Bivariate GARCH Model}

The time-varying hedge ratios are estimated using the following BGARCH models. Bivariate GARCH(p,q) model is applied to returns from the cash and futures markets, express as:

$$
\begin{gathered}
y_{t}=\mu+\delta\left(\mathrm{z}_{t-1}\right)+\varepsilon_{t} \\
\varepsilon \mid \Omega_{t-1} \sim N\left(0, H_{t}\right) \\
\operatorname{vech}\left(H_{t}\right)=C+\sum_{i=1}^{p} A_{i} \operatorname{vech}\left(\varepsilon_{t-i}\right)^{2}+\sum_{j=1}^{q} B_{j} \operatorname{vech}\left(H_{t-j}\right)
\end{gathered}
$$

Where $y_{t}=\left(r_{t}^{c}, r_{t}^{f}\right)$ is a $(2 \mathrm{X} 1)$ vector, $H_{t}$ is a $(2 \times 2)$ conditional covariance matrix, $A_{i}$ and $B_{j}$ are $(3 \times 3)$ parameter matrices, $\mathrm{C}$ is a $(3 \mathrm{x} 1)$ constant parameter vector. Besides, vech is the column-stacking operator that stacks the lower triangular portions of a symmetric matrix. $Z_{t}$ is the error correction term (ECM), represents the short-run deviations from a long-run relationship between the spot price and the futures price. A significant and positive coefficient $\delta$ indicates that an increase in short-run deviations raises the log difference of spot and/or future price.

By imposing a diagonal restriction on the parameter matrices, each variance and covariance element depends only on its own past values and prediction errors. A diagonal vech bivariate $\operatorname{GARCH}(1,1)$ conditional variance equation is as follows:

$$
\begin{gathered}
H_{11, t}=C_{1}+A_{11}\left(\varepsilon_{1, t-1}\right)^{2}+B_{11}\left(H_{11, t-1}\right) \\
H_{12, t}=C_{2}+A_{22}\left(\varepsilon_{1, t-1}, \varepsilon_{2, t-1}\right)^{2}+B_{22}\left(H_{12, t-1}\right) \\
H_{22}=C_{3}+A_{33}\left(\varepsilon_{2, t-1}\right)^{2}+B_{33}\left(H_{22, t-1}\right)
\end{gathered}
$$


Using the bivariate GARCH model, the time-varying hedge ratio can be expressed as:

$$
\hat{h}_{t}=\frac{\hat{H}_{12, t}}{\hat{H}_{22, t}}
$$

in which $\hat{H}_{12, t}$ is the estimated conditional covariance between the spot and futures returns, $\hat{H}_{22, t}$ is the estimated conditional variance of futures returns. The optimal hedge ratio would be time-varying because of the conditional covariance is time-varying. Therefore, this method can be imposed to estimate the dynamic hedge ratio.

\section{Empirical Evidence}

\subsection{Data}

The market that we analyze is the gold market in China. We employ futures prices obtained from the SHFE (Shanghai Futures Exchange) and spot prices sourced from the SGE (Shanghai Gold Exchange) website. The time period covered was from January 2014 to June 2015. Besides, single futures contract were discontinuous, therefore we design continuous-time data. Then, because of the strong tendency of future gold price and gold spot price, we apply logarithm process to the price data so as to weaken the effect of tendency and heteroscedasticity. The major software we used in this paper is Eviews 7.0.

\subsection{ADF Test}

It should be noted that only time series are stationary can we analyze it and estimate its future tendency. Therefore, before constructing the models, it is necessary to have a stationary test. In this paper we use ADF test for unit root, and Table 1 presents the results.

Table 1. Unit root test before and after first order difference

\begin{tabular}{lcccccc}
\hline Variable & \multicolumn{3}{c}{ Level-value test results } & \multicolumn{3}{c}{ First order difference test } \\
\hline & Test pattern & ADF value & P value & Test pattern & ADF value & P value \\
F & $(\mathrm{C}, 0,12)$ & -2.183145 & 0.2180 & $(\mathrm{C}, 0,12)$ & -22.0328 & 0.0000 \\
$\mathrm{~S}$ & $(\mathrm{C}, 0,12)$ & -2.062133 & 0.2543 & $(\mathrm{C}, 0,12)$ & -22.16215 & 0.0000 \\
\hline
\end{tabular}

Notes. Significant at the $5 \%$ level.

As which can be seen in the table1, with significance at the 5\% level, all variables are nonstationary. However, after first order difference, variables show stationary. The result of the unit root test shows that the gold futures and spot golds time series are both nonstationary time series, but they are found to be order one. Variables after first order difference are denfined as IF and IS respectively.

\subsection{Estimate Based on OLS Model}

Traditional regression model to estimate the hedge ratio is mainly through OLS method. In this case changes in spot gold price is regressed on the changes in gold futures price. Using OLS method to estimate optimal hedge ratio, results are given in Table 2:

Table 2. Hedge ratio results through OLS method

\begin{tabular}{lccc}
\hline & Coefficient & T statistic & P value \\
\hline C & $-6.02 \mathrm{E}-04$ & -0.316615 & 0.7882 \\
$\mathrm{IF}$ & 0.892431 & 52.09453 & 0.0000 \\
\hline
\end{tabular}

According to the results, we can find that the regression is significant ( $\mathrm{P}$ value is equal to 0 ), thereby the OLS method is effective. The results indicate that we are supposed to usea unit of 0.892431 opposite future position to hedge 1 unit spot position, i.e. the optimal hedge ratio is 0.892431 .

\subsection{Estimate Based on ECM Model}

After first order difference, the series of spot and of future are uniformity-integrated variables, which is the 
precondition of co-integration test.

Table 3. Hedge ratio results based on ECM method

\begin{tabular}{lccc}
\hline & Coefficient & T statistic & P value \\
\hline C & $4.66 \mathrm{E}-05$ & -0.235217 & 0.7986 \\
$\mathrm{IF}$ & 0.905663 & 56.312092 & 0.0000 \\
\hline
\end{tabular}

With a significance level of $5 \%$, the hedge ratio is equal to 0.988 estimating through ECM method. Comparing it with the results of OLS method, it preforms better. According to the Table 3, we conclude that the regression is significant. The ECM model estimates that for 1 unit spot position, a unit of 0.90 future position is needed for hedge. This provides strong evidence that the optimal hedge ratios obtained by using ECM model do a better job than OLS model.

\subsection{Interventions or Manipulation Fidelity}

If interventions or experimental manipulations were used, provide evidence on whether they were delivered as intended. In basic experimental research, this might be the result of checks on the manipulation. In applied research, this might be, for example, records and observations of intervention delivery sessions and attendance records.

\subsection{Estimate Based on VECM Model}

Firstly, make quantitative analysis through the co-integration test to research the relationship between the spot and future. Through AIC and SC, we determine lag phase is 3. After time series co-integration test (using the Johansen Co-integration test), both trace test and maximum eigenvalue test show they are co-integration.

Table 4. Results of co-integration test

\begin{tabular}{lccc}
\hline & Maximum eigenvalue & Trace test & P value \\
\hline None co-integration relationship & 0.032175 & 19.82351 & 0.0107 \\
At least one integration relationship & 0.009902 & 4.738394 & 0.0297 \\
\hline
\end{tabular}

According to the results through VECM model, the hedge ratio equals to 0.989322 , which is bigger than the results from OLS model and ECM model. These results are consistent with previous research. However, the hedge ratio is still static, so we have to move on a better dynamic model.

In order to calculate time-varying hedge ratio, in this part we employ ECM-BGARCH $(1,1)$ model. Maximum likelihood estimate is used, come out with the mean equation, conditional standard volatility and time - varying variance. Initially the hedge ratio will be calculated according to time - varying conditional variance and conditional covariance.

First and foremost, ARCH effects are tested (as shown in Table 5). Obviously, according to the table, we reject null hypothesis and there are $\mathrm{ARCH}$ effects in the case, so we move to the next step to estimate GARCH equation.

Table 5. Results of ARCH text

\begin{tabular}{llll}
\hline F-statistic & 38.84900 & Prob.F(3,472) & 0.0000 \\
Obs ${ }^{*}$ R-squared & 94.70985 & Prob.Chi-Square(3) & 0.0000 \\
\hline
\end{tabular}

As shown in the Figure 3 and Figure 4 below, conditional variance and conditional covariance vary as time changing; therefore we can speculate that hedge ratio changing by time as well. 


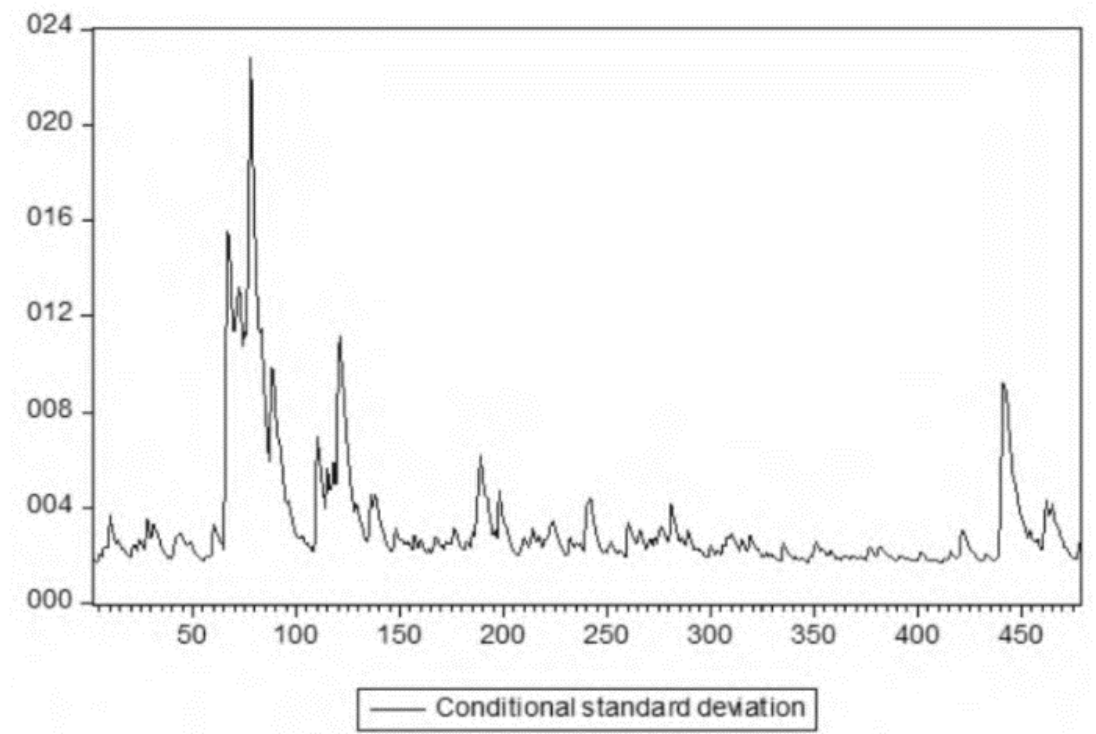

Figure 1. Time-varying conditional standard deviation of IF

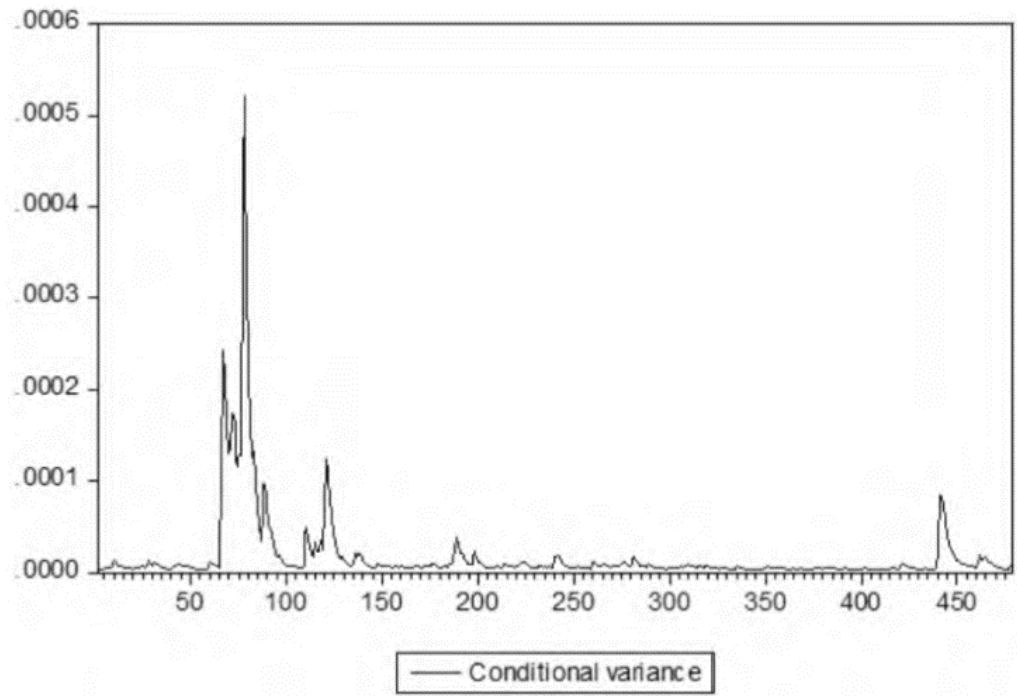

Figure 2. Conditional variance of IF

Time-varying hedge ratio results through ECM-BGARCH$(1,1)$ are shown in Table 6. According to Table 6, the mean of time-varying hedge ratio through ECM-BGARCH model is 0.899703 , which between OLS results and ECM results. Besides, time-varying hedge ratio has fluctuation according to the standard deviation, maximum and minimum. The results are accordance with practical situation.

Table 6. Results of time-varying hedge ratio based on ECM-BGARCH model

\begin{tabular}{lcccc}
\hline Model & Mean of hedge ratio & Standard deviation of hedge ratio & Maximum of hedge ratio & Minimum of hedge ratio \\
ECM -BGARCH & 0.898901 & 0.110243 & 0.616822 & 1.214479 \\
\hline
\end{tabular}

\subsection{Results Comparison and Discussion}

We gather four different hedge ratios estimated by four model all together and draw graph for better comparison(as shown in Figure 3). 


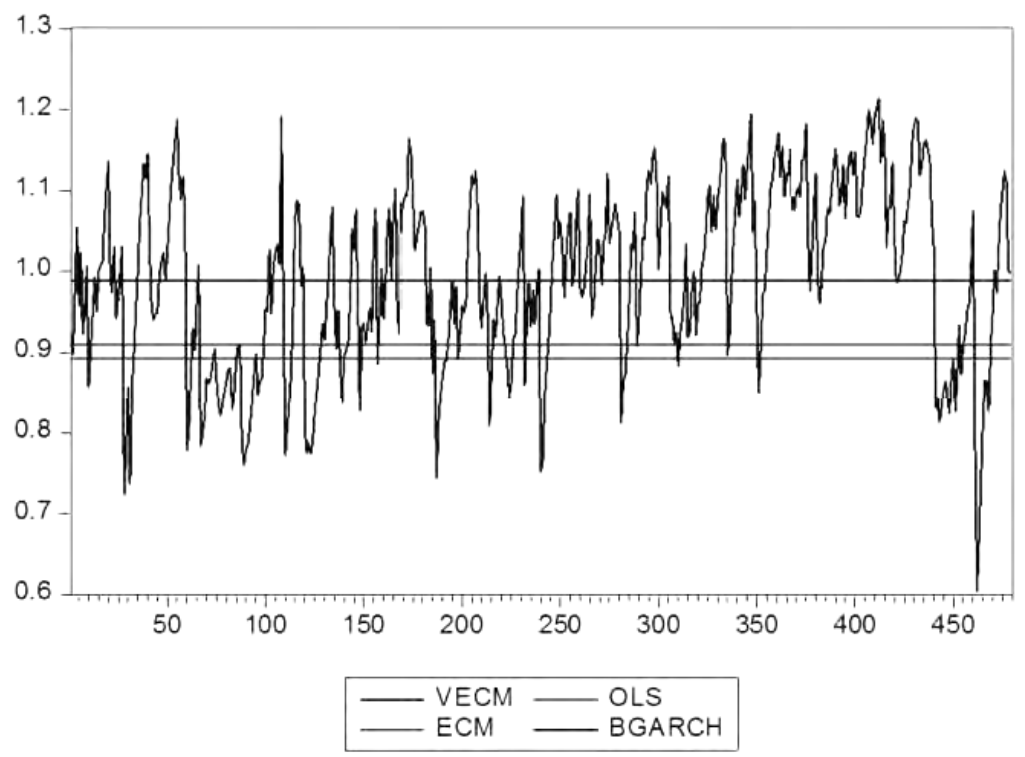

Figure 3. Time-varying hedge ratio comparison of different model

According to Figure 3, the time-varying hedge ratios through ECM-BGARCH model are higher than those from the other three model in most cases over the sample period, which is 0.892431, 0.905663, 0.989322 for OLS model, ECM model and VECM model respectively. This results indicate that static method underestimate the number of needed future contracts. In other words, dynamic ECM-BGARCH model enjoys more efficiency in avoiding spot risk than static method and can provide better practical reference.

Various models of optimal hedge ratio results are shown in Table 7.

Table 7. Results comparison under different model

\begin{tabular}{lccc}
\hline Method & Mean & Variance & Hedge ratio \\
\hline No hedge & -0.000124 & 0.001905 & 0 \\
OLS & $1.78 \mathrm{E}-06$ & 0.000765 & 0.892431 \\
ECM & $1.37 \mathrm{E}-06$ & 0.000763 & 0.905663 \\
VECM & $1.44 \mathrm{E}-06$ & 0.000761 & 0.989322 \\
ECM-BGARCH & $-1.10 \mathrm{E}-05$ & 0.000743 & 0.898901 \\
\hline
\end{tabular}

Observing comparison of different models in the sample period can be seen as follows:

(1) Employing model, regardless of whether static method or dynamic model, are better than no hedge ones.

(2) From the table presented the risk(represented by Variance) is minimum when using ECM-BGARCH model, appearing that the efficiency of ECM-BGARCH model is the best among the four model. Dynamic method can improve the hedge efficiency and effectively averse the risk of cash markets.

\section{Conclusion}

We estimate the optimal hedge ratio in China gold market through four different models with minimum variance method. In static method, the optimal hedge ratios are 0.892431, 0.905663, 0.989322 through OLS model, ECM model and VECM model respectively. The drawback of these three methods is the results are all constant while the hedge ratios are supposed to be time-varying. Base on ECM-BGARCH, we estimate the optimal hedge ratio and obtain the time-varying hedge ratio series. It can be seen from the results that hedge effectiveness dynamic model was significantly better than the static model. With dynamic model, we overcome drawbacks of traditional static method that assuming the variance is constant, and revel the feature of continuous Shanghai gold futures that returns rate is time-varying. Through this method we successfully improve the hedge effect.

The empirical results show ECM-BGARCH have the best performance, not only improve the efficiency of hedge but avoid risk. The results of this paper have practical value on China's gold transaction to avoid the risk, perfect gold futures markets and improve the efficiency of hedge. It also provides reference in other futures markets for 
hedging in China.

\section{References}

Bail, L., \& Myers, R. J. (1991). Estimating Time Varying Optimal Hedge Ratios on Futures Markets. Journal of Futures Markets. http://dx.doi.org/10.1002/fut.3990110105

Balke, N. S., \& Fomby, T. B. (1997). Threshold cointegration. International Economic Review. http://dx.doi.org/10.2307/2527284

Chen, K. C., Sears, R. S., \& Tzang, D. (1987). Oil prices and energy futures. The Journal of Futures Markets. http://dx.doi.org/10.1111/j.1540-6288.1987.tb01165.x

Chou, W., Denis, K., \& Lee, C. (1996). Hedging with the Nikkei index futures: The conventional versus the error correction model. The Quarterly Review of Economics and Finance, 36, 495-505. http://dx.doi.org/10.1016/S1062-9769(96)90048-4

Ederington, L. H. (1979). The hedging performance of the new futures markets. The Journal of Finance, 34, 157-170. http://dx.doi.org/10.1111/j.1540-6261.1979.tb02077.x

Ghosh, A. (1993). Hedging with stock index futures: Estimation and forecasting with error correction model. The Journal of Futures Markets, 13, 743-752. http://dx.doi.org/10.1002/fut.3990130703

Hongfeng, P., \& Yonggang, Y. (June, 2007). Empirical research on optimal hedge ratio of copper futures in China. Wuhan University Journal.

Hsiang-Tai, L., \& Yoder, J. K. (2007). A bivariate Markov regime switching GARCH approach to estimate time varying minimum variance hedge ratios. Applied Economics, 39(10), 1253-1265. http://dx.doi.org/10.1080/00036840500438970

Johnson, L. (1960). The theory of hedging and speculation in commodity futures. Review of Economics Studies, 27, 139-151. http://dx.doi.org/10.1007/978-1-349-02693-7_4

Kroner, K. F., \& Sultan, J. (1993). Time-varying distributions and dynamic hedging with foreign currency future. Journal of Financial and Quantitative Analysis, (28), 535-551. http://dx.doi.org/10.2307/2331164

Lianqian, Y.,, \& Bo, L. (2013). The Hedging Practice with Chinese Energy Futures. International Journal of Ecological Economics and Statistic.

Malliaris, A. G., \& Urrntial, J. (1989). Test of Random Walk of the Hedge Ratio and Measuring Effectirenss for Stock Indexes and Foreign Current Contracts. Chicago: Working Paper 8908, Loyola University.

Manolis, G. K., \& Nikos, K. N. (2000). Constant vs. time-varying hedge ratios and hedging efficiency in the BIFFEX market. Transportation Research, 36, 229-248. http://dx.doi.org/10.1016/S1366-5545(99)00029-0

Stein, J. L. (1961). The simultaneous determination of spot and futures price. American Economic Review. http://dx.doi.org/10.1007/978-1-349-02693-7_7

Taufiq, C., \& Yuan, Y. Z. (2013). Forecasting the Daily Dynamic Hedge Ratios by GARCH Models: Evidence from the Agricultural Futures Markets. The European Journal of Finance.

Wang, J., \& Zongcheng, Z. (2005). Empirical research on hedging performance of China hard wheat and soybean futures market. Journal of China Agricultural University, (4).

Working H. (1962). New concepts concerning futures markets and Prices. American Economic Review, 52, $43-45$.

\section{Copyrights}

Copyright for this article is retained by the author(s), with first publication rights granted to the journal.

This is an open-access article distributed under the terms and conditions of the Creative Commons Attribution license (http://creativecommons.org/licenses/by/3.0/). 